Letter to Editor

OPen Access

D) CrossMark

\title{
Obese patients: general or combined anaesthesia?
}

\author{
Volume I Issue 6 - 2014
}

\section{Letter to editor}

In comparison with general anaesthesia, numerous studies have found that combined anaesthesia provides better analgesic quality and presents fewer cases of postoperative respiratory failure. ${ }^{1}$ The use of combined general and epidural anaesthesia is well understood and commonly applied. This approach decreases anaesthetic requirements, makes it possible to carry out a postoperative analgesic strategy, can lower the blood loss and reduces postoperative complications such as respiratory failure and thrombosis., ${ }^{2,3}$ Therefore, it is particularly indicated for obese patients undergoing surgical interventions, especially if a high rate of postoperative pain is to be expected. ${ }^{4}$

A good example of this situation is the patient who was treated at our hospital for a giant post-laparotomy hernia (Figures $1 \& 2$ ). This man, aged 52 years, had a clinical history of morbid obesity, obstructive sleep apnoea and intervention for appendicitis. Evaluation by the Mallampati test II revealed no predictor of difficult airway. An epidural catheter was inserted in the L2-L3 space, for Intraoperative analgesia. Small and large bowel loops were released from the hernia sac and reintroduced into the cavity. The bowel wall was then repaired by closing the sac flaps and inserting a mesh (Figures 3 \& 4). Postoperative pain was controlled by an epidural infusion of ropivacaine plus fentanyl and rescue non steroidal anti-inflammatory drugs (NSAIDs). The patient reported good pain control and at 48 hours post-surgery the catheter was removed. The postoperative course was satisfactory and the patient was discharged from hospital after five days without incident of note.

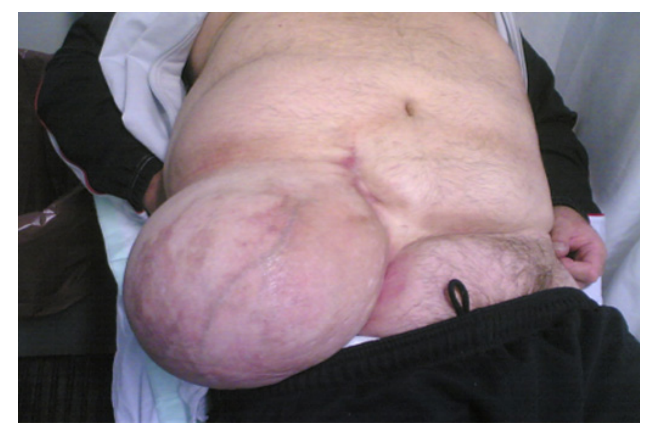

Figure I Giant post-laparotomy hernia.

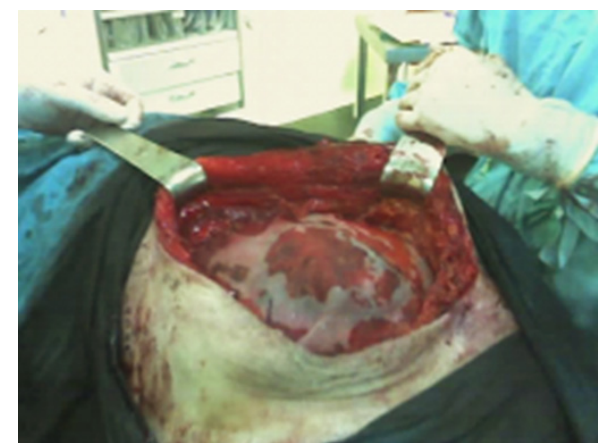

Figure 2 Giant post-laparotomy hernia.

\author{
Pérez Lara FJ,' Ramos Martinez E, ${ }^{2}$ Del Rey \\ $A,{ }^{3}$ Oliva Muñoz ${ }^{4}$ \\ 'Digestive Surgeon, Antequera Hospital, Spain \\ ${ }^{2}$ Anesthesiologist, Antequera Hospital, Spain \\ ${ }^{3}$ UGC Director, Antequera Hospital, Spain \\ ${ }^{4}$ Chief of Surgery Service, Antequera Hospital, Spain
}

Correspondence: Francisco Javier Pérez Lara, Hospital de Antequera, Secretaría de Cirugía ( $3^{\circ}$ planta), Avenida Poeta Muñoz Rojas s/n, Antequera, Málaga, 29200, Spain, Tel 34637322133,Email javinewyork@hotmail.com

Received: December 06, 2014 | Published: December 24, 2014

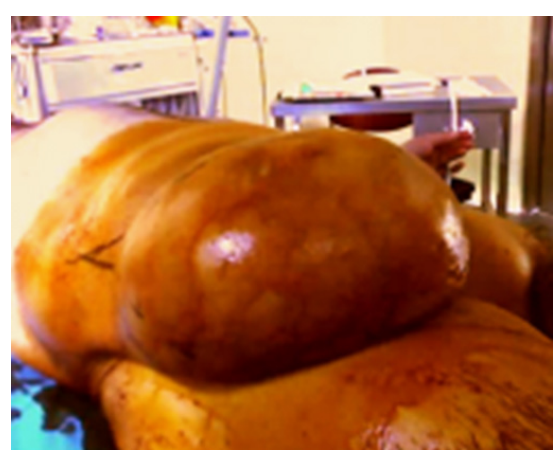

Figure 3 Bowel wall repaired by closing the sac flaps and inserting a mesh.

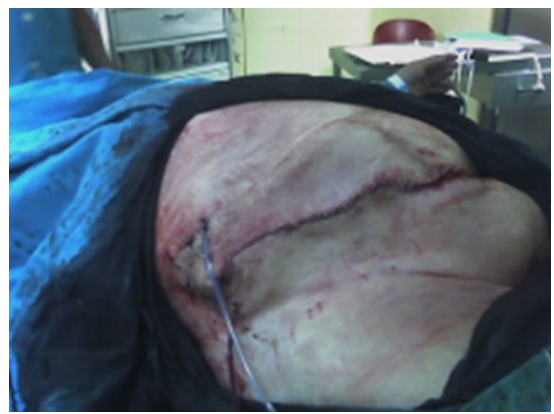

Figure 4 Final outcome. 
Given the patient's background of obesity and respiratory problems, and the large size of the hernia and the possible duration of the intervention, we decided to apply combined anaesthesia, and thus obtain the advantages of epidural analgesia, i.e., less bleeding, better pain control, lower incidence of thrombotic events and fewer respiratory problems, among others.

\section{Conclusion}

We believe that for obese patients undergoing significant interventions, especially if they have respiratory problems or present a high risk of thrombosis, combined analgesia would be indicated (if anaesthesiologist has enough experience), thus improving comfort and reducing postoperative risks.

\section{Funding details}

None.

\section{Acknowledgments}

None.

\section{Conflicts of interest}

Authors declare that there is no conflicts of interest.

\section{References}

1. Clarke H, Chandy T, Srinivas C, et al. Epidural analgesia provides better pain management after live liver donation:A retrospective study. Liver Transpl. 2011;17(3):315-323.

2. Wu CL, Cohen SR, Richman JM, et al. Efficacy of Postoperative Patient-controlled and Continuous Infusion Epidural Analgesia versus Intravenous Patient-controlled Analgesia with Opioids A Metaanalysis. Anesthesiology. 2005;103(5):1079-1088.

3. Khajavi MR, Asadian MA, Imani F, et al. General anesthesia versus combined epidural/general anesthesia for elective lumbar spine disc surgery:A randomized clinical trial comparing the impact of the two methods upon the outcome variables. Surg Neurol Int. 2013;4:105.

4. Seller Losada JM, Sifre Julio C, Ruiz Garcia V. Combined generalepidural anesthesia compared to general anesthesia:a systematic review and meta-analysis of morbidity and mortality and analgesic efficacy in thoracoabdominal surgery. Rev Esp Anestesiol Reanim. 2008;55(6):360-366. 